\title{
Simulation of the suppressive effect of zinc on cyanobacteria in paper mill wastewater
}

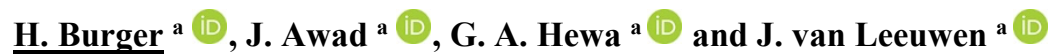 \\ ${ }^{a}$ School of Natural and Built Environments, University of South Australia, Adelaide, Australia \\ Email: Hugh.Burger@unisa.edu.au
}

\begin{abstract}
Harmful algal blooms (i.e. blue-green algae or cyanobacteria) and their impacts are a recurring and significant issue worldwide. Factors supporting the extensive growth of cyanobacteria include warmer temperatures, sufficient levels of reactive nitrogen and phosphorus, reduced rainfall, long hydraulic retention times within the water body (slow-moving water) and adequate sunlight. Problems associated with the growth of cyanobacteria include formation of unpleasant odours and toxins that have the potential to harm humans and wildlife that come into contact with contaminated water.
\end{abstract}

Aerated stabilization basin (ASB) systems, commonly used by the pulp and paper mill industry for treatment of wastewater, are predominantly light limited due to high colour and consequently, blooms of cyanobacteria have been reported to rarely occur in pulp and paper ASBs. However, with the relatively low colour of paper mill (PML) wastewater (without integrated pulping processes) in ASB treatment with long hydraulic retention times (HRTs), there would be risk of occurrence of cyanobacteria at bloom levels. In 2014, two occurrences of cyanobacterial blooms were observed at a PML site in South Australia and in April 2016, Microcystis aeruginosa occurred at bloom levels $\left(>10^{6}\right.$ cells $/ \mathrm{mL}$ ) in an ASB pilot plant (3 tanks of $\sim 200 \mathrm{~L}$ each) operated at the PML site to simulate the full scale ASB operation. Following these incidences, it was evident that there is need for improved understanding and modelling of strategies to control cyanobacteria present in PML wastewaters.

The aim of the research reported here was to establish models that describe the dynamics of cyanobacteria presence, indicated by phycocyanin, in PML wastewaters when exposed to zinc. This was investigated based on the inhibitory effect of $\mathrm{Zn}$ on cyanobacteria. In this research, batch experiments were conducted using a strain of Microcystis aeruginosa (MA338) and Pseudanabaena spp. (naturally occurring) in samples collected from ASB wastewaters. Growth and inhibition of the cyanobacteria were assessed by fluorometric detection of phycocyanin (using an EXO1 sonde with EXO Total Algae PC Smart Sensor), which is a cyanobacterial specific pigment that increases linearly with cyanobacterial biomass increase.

Phycocyanin levels were determined for batch experiments where $\mathrm{Zn}$ was dosed at between 0.3 and $2.4 \mathrm{mg} / \mathrm{L}$ and in controls, for 7 days. At lower concentration $(\sim 0.3 \mathrm{mg} / \mathrm{L}), \mathrm{Zn}$ was found to be supportive for the growth of MA338 based on phycocyanin data. In contrast, $\mathrm{Zn} \geq 0.7 \mathrm{mg} / \mathrm{L}$ was found to be effective in suppressing the cyanobacteria tested in this study. For test samples (with $\mathrm{Zn} \geq$ of $0.7 \mathrm{mg} / \mathrm{L}$ ), two functions [exponential peak (EP) and logistic dose response (LDR)] were fitted to \% phycocyanin vs time data. From the collected data at initial and on days 1, 3, 4 and 7, the phycocyanin reduction (decay) rates at the various $\mathrm{Zn}$ doses $(0.7 \leq \mathrm{Zn} \leq$ $2.4 \mathrm{mg} / \mathrm{L})$ were determined. The reduction rates $(\Delta \% \mathrm{Phy} / \Delta$ time $)$ differ between the two models but trended consistently (EP: 52, 64, 85, 164 and LDR: 85, 249, 188, 1621 for Zn concentrations of 0.7, 1.1, 1.6 and 2.4 $\mathrm{mg} / \mathrm{L}$, respectively).

The two models broadly described the dynamics of phycocyanin levels in samples of PML wastewaters in response to $\mathrm{Zn}$ exposure up to $2.4 \mathrm{mg} / \mathrm{L}$ over 7 days. Both models differ in their fittings over the first few days to $\mathrm{Zn}$ exposure, where the EP model correctly describes an increase in phycocyanin after initial $\mathrm{Zn}$ exposure. However, the maximum level estimated by this approach is speculative of what is the true maximum value, and for this much finer resolution data would be needed over the early stage of batch experiments. Further investigation is needed to determine the $\mathrm{Zn}$ concentration with exposure time that would suppress or enhance cyanobacteria growth and the fate of $\mathrm{Zn}$ in PML ASB systems. Integrated modelling with phycocyanin monitoring has the potential to better implement strategies for cyanobacterial control, through rapid assessment of the responses and efficiencies of chemicals applied to inhibit cyanobacteria growth.

Keywords: Microcystis aeruginosa, ASB, phycocyanin, dose response modelling 


\section{INTRODUCTION}

Human exposure to cyanobacterial blooms has been associated with gastroenteritis, fever, dermatitis, irritation of the eyes, nose and throat (World Health Organization, 2015), as well as risks to liver cancer, liver damage and neurological damage (Butler et al., 2009; Iwinski et al., 2016). Cyanobacteria are photoautotrophic, and light is the key factor for their growth, followed by nutrients levels (Kirkwood et al. 2003). Kirkwood et al. (2003) reported that pulp and paper aerated stabilization basin (ASB) systems are severely light limited, and cyanobacterial blooms have been reported to rarely occur in pulp and paper ASBs because of the dark colour of wastewaters and mixing of waters by aerators (Mahmood \& Paice 2006). However, with the discontinuation of on-site pulping and use of imported pulp only for paper production, the wastewaters of the mill studied become relatively low in colour. Further, with subsequent reduction in wastewater volumes, the hydraulic retention times (HRTs) of the established ASB became much longer and hence with sufficient nutrients and wastewater clarity, there is an increased risk of occurrence of cyanobacterial blooms (Lewis et al. 2018).

In 2014, cyanobacterial blooms (comprising Pseudanabaena spp. Phormidium spp. Microcystis flos-aquae, Planktolyngbya spp. Aphanocapsa spp.) were observed in a full scale ASB system of a paper mill, where the colour of the wastewaters was low. Prior to the ASB, the wastewaters were treated by a settling clarifier for removal of suspended solids. In a pilot plant ( 3 tanks of $\sim 200 \mathrm{~L}$ each) operated at the PML site to simulate the full scale ASB operation, Microcystis aeruginosa occurred at bloom levels in April 2016 (>10 $0^{6}$ cells $\left./ \mathrm{mL}\right)$. For drinking water resources established control methods for cyanobacteria growth include the use of stabilised hydrogen peroxide and copper (e.g. copper sulphate), and novel methods explored including ultrasonication.

The toxicities of heavy metals to cyanobacteria, such as copper $(\mathrm{Cu})$, cadmium $(\mathrm{Cd})$, nickel $(\mathrm{Ni})$ and zinc $(\mathrm{Zn})$ have been previously reported (e.g. Polyak et al., 2013; Zeng and Wang, 2011). Zeng and Wang, (2011) reported the capacity of cyanobacteria to uptake $\mathrm{Zn}, \mathrm{Cu}$ and $\mathrm{Cd}$ in BG-11 growth media. Polyak et al., (2013) reported the concentrations of $\mathrm{Cu}, \mathrm{Ni}$ and $\mathrm{Zn}$ that suppressed growth of two strains of Microcystis aeruginosa isolated from a lake in Russia, as well as reporting that low $\mathrm{Zn}$ concentrations supported their growth. Currently there is minimal information on the impact of $\mathrm{Zn}$ on cyanobacteria in PML wastewaters of ASB systems.

Here we report the impact of $\mathrm{Zn}$ on cyanobacteria based on phycocyanin detection by fluorometric probe. In this paper, we describe the modelling of phycocyanin levels under laboratory conditions conducted to determine the impact of $\mathrm{Zn}$ on cyanobacterial growth and decline in PML wastewater. We propose that this modelling approach integrated with in-situ phycocyanin detection enables improved understanding of $\mathrm{Zn}$ as a potential cyanobacterial control agent and where it occurs as a background metal in industrial wastewaters.

\section{METHODOLOGY AND APPROACH}

To study the effect of $\mathrm{Zn}$ on the growth or inhibition of cyanobacteria in PML wastewaters, batch sample experiments were conducted with $\mathrm{Zn}$ addition between 0.3 and $2.4 \mathrm{mg} / \mathrm{L}$, and without $\mathrm{Zn}$ addition as controls. These were conducted under laboratory conditions, with temperatures ranging from $20^{\circ} \mathrm{C}$ to $29^{\circ} \mathrm{C}$, LED lighting (18 x type 5730 LEDs producing 1125 lumens) at $12 \mathrm{~h}$ on/off cycles, initial pH level of $7.9 \pm 0.4$, and initial dissolved oxygen (DO) level of $8.2 \pm 0.3 \mathrm{mg} / \mathrm{L}$, typical of the paper mill studied. Growth and inhibition of the cyanobacteria were assessed by fluorometric detection of phycocyanin (using an EXO1 ${ }^{\mathrm{TM}}$ sonde with EXO Total Algae PC Smart Sensor). Each experiment was conducted over 7 days and measurements were taken at the start and days $1,3,4$ and 7 .

Wastewater samples were collected from a paper mill ASB (discharge of the third pond of a three-pond system) and from the inflow to the ASB (settling clarifier) having $\mathrm{Zn}$ concentrations of 0.058 and $0.117 \mathrm{mg} / \mathrm{L}$, respectively, in May 2018.

To study the effects of different inhibitory concentrations of $\mathrm{Zn}$, two sets of wastewaters (for experiment (Expt) \#1-1: inflow; \#1-2: outflow waters) were initially inoculated with Microcystis aeruginosa (strain MA338, sourced from the AWQC, SA) in ASM-1 (Gorham et al. 1964) then dosed with a range of Zn concentrations to achieve concentrations $0.3-2.4 \mathrm{mg} / \mathrm{L}$. Zinc was added from a stock solution $(2,580 \mathrm{mg} / \mathrm{L})$ prepared using Analytical Grade zinc chloride (Alfa Aesar, Thermo Fisher Scientific Australia Pty Ltd) or pure Zn (99.9\%). The highest level of the $\mathrm{Zn}$ range tested is $\sim 50 \%$ of the $5.0 \mathrm{mg} / \mathrm{L}$ guideline limit for recreational waters under the Australian and New Zealand Guidelines for Fresh and Marine Water Quality (ANZECC, 2000).

In a subsequent experiment, $\mathrm{Zn}(2.4 \mathrm{mg} / \mathrm{L})$ was used to examine the effect of initial cyanobacteria level, as detected phycocyanin (\#2-1: $\sim 86 \pm 2.9 \mu \mathrm{g} / \mathrm{L}$ compared with \#2-2: 46 $\pm 4.9 \mu \mathrm{g} / \mathrm{L}$ ) on the effect of zinc on $M$. aeruginosa (MA338). Further, the effect of $\mathrm{Zn}($ at $2.4 \mathrm{mg} / \mathrm{L}$ ) on two different cyanobacteria species (\#3-1: Pseudanabaena spp.; \#3-2: MA338) were also examined. A culture of Pseudanabaena spp. was obtained from the ASB and grown in ASM-1 media. These cyanobacteria were chosen as these species occurred naturally at 
Burger et al., Simulation of the suppressive effect of zinc on cyanobacteria in paper mill wastewater

the study site at bloom proportions $\left(>10^{6}\right.$ cells $\left./ \mathrm{mL}\right)$. Source waters, initial phycocyanin and initial culture cell counts for each experiment are given in Table 1.

Table 1. Source waters, initial phycocyanin and culture cell counts for each set of experiments

\begin{tabular}{|c|c|c|c|c|c|c|}
\hline No. & Source water & $\begin{array}{l}\text { Culture } \\
\text { Cyanobacteria }\end{array}$ & Purpose & $\begin{array}{l}\text { Culture } \\
\text { cell } \\
\text { counts }\end{array}$ & $\begin{array}{l}\text { Initial } \\
\text { phycocyanin } \\
(\mu \mathrm{g} / \mathrm{L})\end{array}$ & $\begin{array}{l}\text { Initial } \quad \mathrm{Zn} \\
\text { concentration(s), } \\
(\mathrm{mg} / \mathrm{L})\end{array}$ \\
\hline $1-1$ & Inflow to ASB & MA338 & \multirow{2}{*}{$\begin{array}{l}\text { Zn concentration } \\
\text { determination }\end{array}$} & $4.2 \times 10^{4}$ & $24.9 \pm 2.8$ & $0.3 \pm 0.02: 2.4 \pm 0.1$ \\
\hline $1-2$ & Pond 3 of ASB & MA338 & & $4.2 \times 10^{4}$ & $22.8 \pm 2.1$ & $0.3 \pm 0.02: 2.4 \pm 0.1$ \\
\hline $2-1$ & Pond 3 of ASB & MA338 & \multirow{2}{*}{$\begin{array}{l}\text { Zn effect with cell } \\
\text { number }\end{array}$} & $2.88 \times 10^{6}$ & $86.4 \pm 2.9$ & 2.5 \\
\hline $2-2^{*}$ & Pond 3 of ASB & MA338 & & $2.88 \times 10^{6}$ & $45.6 \pm 4.9$ & $2.5 \pm 0.1$ \\
\hline $3-1^{*}$ & Pond 3 of ASB & Pseudanabaena spp. & \multirow{2}{*}{$\begin{array}{l}\text { Triplicate test with } \\
\mathrm{Zn} \text { at } 2.5 \mathrm{mg} / \mathrm{L}\end{array}$} & $7.61 \times 10^{6}$ & $25.7 \pm 0.9$ & $2.5 \pm 0.1$ \\
\hline $3-2^{*}$ & Pond 3 of ASB & MA338 & & $7.50 \times 10^{6}$ & $36.1 \pm 1.1$ & $2.5 \pm 0.05$ \\
\hline
\end{tabular}

\subsection{Modelling of data}

Average phycocyanin levels for samples without $\mathrm{Zn}$ addition (controls) were determined on days $0,1,3,4$ and 7 for each experiment and subsequently were used to compare those with $\mathrm{Zn}$ addition ( $\mathrm{Zn} \geq 0.7 \mathrm{mg} / \mathrm{L})$ at corresponding days. Percentage phycocyanin (\%Phy) values were calculated, normalised to Day 0 values. Two exponential decay functions [exponential peak (EP, Eq. 1) and logistic dose response (LDR, Eq. 2)] equations were used to model fit the \%Phy values for the various $\mathrm{Zn}$ doses, using TableCurve ${ }^{\mathrm{TM}}$ software. The equations were chosen based on the likelihood of these theoretically representing the release and reduction (loss) of phycocyanin with the inhibitory action of $\mathrm{Zn}$ on cyanobacteria (Poliak et al. 2011; Polyak et al. 2013). Coefficients of these equations were acquired by statistical analysis.

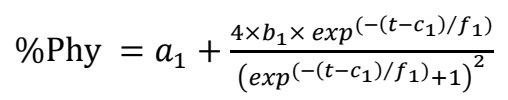

Where, $\mathrm{t}$ is the time from $\mathrm{Zn}$ dosing (day); $\mathrm{a}_{1}$ is the minimum \%Phy value (\%); $\mathrm{b}_{1}$ is the difference between the maximum and the minimum \%Phy value $(\%) ; \mathrm{c}_{1}$ is the time $(\mathrm{t})$ from dosing that is required to achieve the maximum \% Phy value; $f_{1}$ is the coefficient of decay.

$$
\% \text { Phy }=a_{2}+\frac{b_{2}}{1+\left(\frac{t}{C_{2}}\right)^{f_{2}}}
$$

Where, $\mathrm{t}$ is the time from $\mathrm{Zn}$ dosing (day); $\mathrm{a}_{2}$ is the minimum \%Phy value (\%); $\mathrm{b}_{2}$ is the difference between the maximum and the minimum \%Phy value (\%); $\mathrm{c}_{2}$ is the time ( $\mathrm{t}$ ) from dosing that is required to achieve the half of the initial Phy\% value; $f_{2}$ is the coefficient of decay.

\section{RESULTS AND DISCUSSION}

For both pre-ASB (clarifier) and ASB (pond 3 discharge) samples, addition of $\mathrm{Zn}$ at concentration of $0.3 \mathrm{mg} / \mathrm{L}$ was found to be supportive (up to day 4) for the growth of MA338. Conversely, addition of $\mathrm{Zn}$ at concentrations between 0.7 and $2.4 \mathrm{mg} / \mathrm{L}$ were found to suppress MA338 based on phycocyanin data (Figures 1 and 2). Coefficients of Eq. 1 and Eq. 2 for the various experiments (with $\mathrm{Zn} \geq 0.7 \mathrm{mg} / \mathrm{L}$ ) conducted are given in Table 2. $\mathrm{R}^{2}$ values were greater than 0.96 for both, indicating that the models well described the observed data acquired. Based on these models, the time required from dosing to achieve half of the initial Phy\% value $\left(\mathrm{t}_{50}\right)$ and to reduce this by $90 \%\left(\mathrm{t}_{90}\right)$ were calculated and summarised in Table 2 . The phycocyanin decay rates at $\mathrm{t}_{50}$ are also shown in Table 2. With increases in the $\mathrm{Zn}$ concentrations $(0.7,1.1,1.6,2.4 \mathrm{mg} / \mathrm{L})$ the modelled phycocyanin reduction (decay) rates $(\Delta \% \mathrm{Phy} / \Delta$ time $)$ are also higher, i.e. the average decay rates for the EP model were 52, 64, 85 and 164 while that for the LDR were 85, 249, 188 and 1621, respectively.

As can be seen from Figures 1 and 2, statistical fitting of the available data to the two equations leads to markedly different decay rates, clearly indicating a need to acquire finer resolution of data between Days 1 and 3 to assess the true decay dynamics. Further, the actual increases in phycocyanin from Day 0, as a response to the $\mathrm{Zn}$ addition, either through cell lysis and/or in a defence response (Poliak et al. 2011) indicates that the LDR is less suitable for such a dose-response condition, where the response is potentially an increase followed by a decline, i.e. the LDR describes no change from an initial fitted value (average from initial and higher values) until a point of decline in reached from that value. 
Burger et al., Simulation of the suppressive effect of zinc on cyanobacteria in paper mill wastewater

Table 2. Models coefficients, and $t_{50}$ and $t_{90}$ values

\begin{tabular}{|c|c|c|c|c|c|c|c|c|c|c|c|c|c|c|}
\hline \multirow{2}{*}{$\begin{array}{l}\text { Expt } \\
\#\end{array}$} & \multirow{2}{*}{$\begin{array}{l}\mathrm{Zn} \\
\text { dose } \\
(\mathrm{mg} / \mathrm{L})\end{array}$} & \multicolumn{7}{|c|}{ Exponential peak model (Eq. ${ }^{\text {b }}$ ) } & \multicolumn{6}{|c|}{ Logistic dose response model (Eq. $\left.2^{c}\right)$} \\
\hline & & $\begin{array}{l}a_{1} \\
(\%)\end{array}$ & $\begin{array}{l}b_{1} \\
(\%)\end{array}$ & $\begin{array}{l}c_{1} \\
\text { (d) }\end{array}$ & $f_{1}$ & $\begin{array}{l}t(d) \text { of } \\
t_{50-1}{ }^{a}\end{array}$ & $\begin{array}{l}t(d) \text { of } \\
t_{90-1}\end{array}$ & $\begin{array}{l}\text { Dec. } \\
\text { rate }_{1}\end{array}$ & $\begin{array}{l}a_{2} \\
(\%)\end{array}$ & $\begin{array}{l}\mathbf{b}_{2} \\
(\%)\end{array}$ & $\begin{array}{l}\mathrm{c}_{2}(\mathrm{~d}) ; \\
\mathrm{t}_{50-2}\end{array}$ & $f_{2}$ & $\begin{array}{l}t(d) \text { of } \\
t_{90-2}\end{array}$ & $\begin{array}{l}\text { Dec. } \\
\text { rate }_{2}\end{array}$ \\
\hline \multirow[t]{4}{*}{$1-1$} & 0.7 & 2.7 & 111 & 0.7 & 0.9 & 2.4 & 4.3 & -40 & 6.0 & 98 & 2.8 & 12.7 & 3.6 & -109 \\
\hline & 1.1 & 0.01 & 110 & 0.6 & 0.9 & 2.3 & 3.9 & -40 & 3.0 & 98 & 2.9 & 17.2 & 3.2 & -226 \\
\hline & 1.6 & 2.1 & 133 & 0.6 & 0.5 & 1.8 & 2.9 & -70 & 2.5 & 108 & 2.6 & 17.2 & 3.0 & -176 \\
\hline & 2.4 & 2.3 & 289 & 0.5 & 0.2 & 1.3 & 1.8 & -181 & 2.5 & 116 & 2.0 & 208 & 2.0 & -2867 \\
\hline \multirow[t]{4}{*}{$1-2$} & 0.7 & 0.3 & 105 & 0.5 & 1.0 & 2.7 & 3.8 & -64 & 2.8 & 96 & 2.7 & 7.2 & 3.8 & -61 \\
\hline & 1.1 & 0.4 & 137 & 0.5 & 0.5 & 1.5 & 2.4 & -87 & 0.5 & 103 & 2.6 & 27.8 & 2.9 & -271 \\
\hline & 1.6 & 0.5 & 149 & 0.5 & 0.4 & 1.5 & 2.2 & -99 & 0.5 & 105 & 2.4 & 18.4 & 2.7 & -200 \\
\hline & 2.4 & 0.01 & 175 & 0.4 & 0.3 & 1.2 & 1.7 & -147 & 0.01 & 100 & 1.1 & 16.2 & 1.2 & -375 \\
\hline $2-1$ & 2.5 & 0.01 & 169 & 0.5 & 0.3 & 1.3 & 1.9 & -125 & 0.1 & 100 & 2.1 & 12.9 & 2.5 & -150 \\
\hline $2-2$ & 2.5 & 0.01 & 111 & -0.2 & 0.3 & 0.3 & 0.8 & -145 & 0.0 & 100 & 0.4 & 3.7 & 0.8 & -210 \\
\hline 3-1 & 2.5 & 0.01 & 132 & 0.4 & 0.3 & 1.1 & 1.7 & -113 & 0.1 & 100 & 1.1 & 6.9 & 1.5 & -158 \\
\hline $3-2$ & 2.5 & 0.01 & 138 & 0.6 & 0.5 & 1.6 & 2.4 & -84 & 0.1 & 106 & 2.4 & 15.1 & 2.8 & -166 \\
\hline
\end{tabular}

${ }^{a} t_{50-1}$ and $t_{50-2}$ are times required from dosing to reduce half of the initial Phy\% value calculated by Eq.1 and Eq.2, respectively. While, $\mathrm{t}_{90-1}$ and $\mathrm{t}_{90-2}$ are times required to reduce $90 \%$ of phycocyanin values calculated by Eq. 1 and Eq.2, respectively. ${ }^{b} \mathrm{R}^{2}$ values were greater than $0.99 ;{ }^{\mathrm{c}} \mathrm{R}^{2}$ values were greater than 0.96
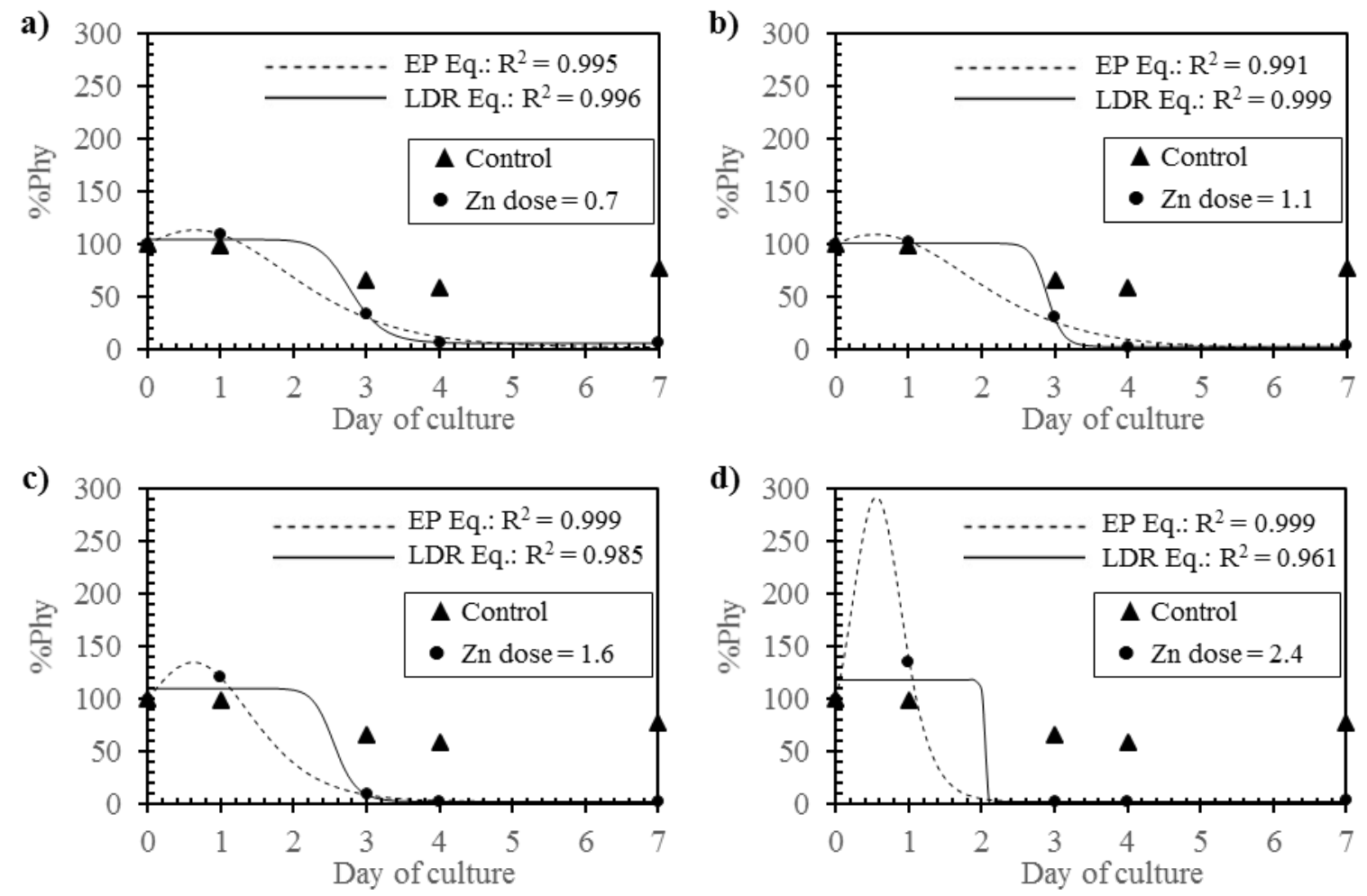

Figure 1. \% Phy levels in pre-ASB waters without and with Zn subsequently added at various concentrations (a) 0.7 , (b) 1.1 , (c) $1.6 \&$ (d) $2.4 \mathrm{mg} / \mathrm{L} \mathrm{Zn}$

In pre-ASB sampled waters (from the clarifier), $\mathrm{Zn}$ was found to be less effective at the tested concentrations than in ASB sampled waters (Pond 3 discharge). This may be due to the use of $\mathrm{Zn}$ as sacrificial anodes increasing the $\mathrm{Zn}$ concentration in the pre-ASB clarifier, compared to the ASB waters. Zeng et al. (2009) found M. aeruginosa acclimatized to and become resistant to $\mathrm{Zn}$ concentrations that would otherwise be toxic. The $\mathrm{t}_{50}$ for pre-ASB waters dosed with $\mathrm{Zn}$ was found to be generally higher at $\mathrm{Zn}$ concentration of $0.7 \mathrm{mg} / \mathrm{L}$ (by EP: $+-13 \%$; by LDR: $+4 \%), 1.1 \mathrm{mg} / \mathrm{L}(+35 \% \&+10 \%), 1.6 \mathrm{mg} / \mathrm{L}(+17 \% \&+8 \%)$ and at $2.4 \mathrm{mg} / \mathrm{L}$ of $\mathrm{Zn}(+8 \%$ vs $+45 \%$ ) than their corresponding $t_{50}$ for ASB waters dosed with $\mathrm{Zn}$. Consistent with the $t_{50}$, the $t_{90}$ values followed the same trend with values higher for pre-ASB sampled waters dosed with $\mathrm{Zn}$ at $0.7 \mathrm{mg} / \mathrm{L}$ (by EP: + $12 \%$; by LDR: $-6 \%), 1.1 \mathrm{mg} / \mathrm{L}(+38 \% \&+9 \%), 1.6 \mathrm{mg} / \mathrm{L}(+24 \% \&+10 \%)$ and at $2.4 \mathrm{mg} / \mathrm{L}$ of $\mathrm{Zn}(+6 \%$ vs $+40 \%$ ) than the corresponding ASB sampled waters. These data indicate that the impact of $\mathrm{Zn}$ on these cyanobacteria in PML wastewaters changes through the ASB, presumably depending on the changing characteristics of the wastewaters, the basis of which requires further investigation. 

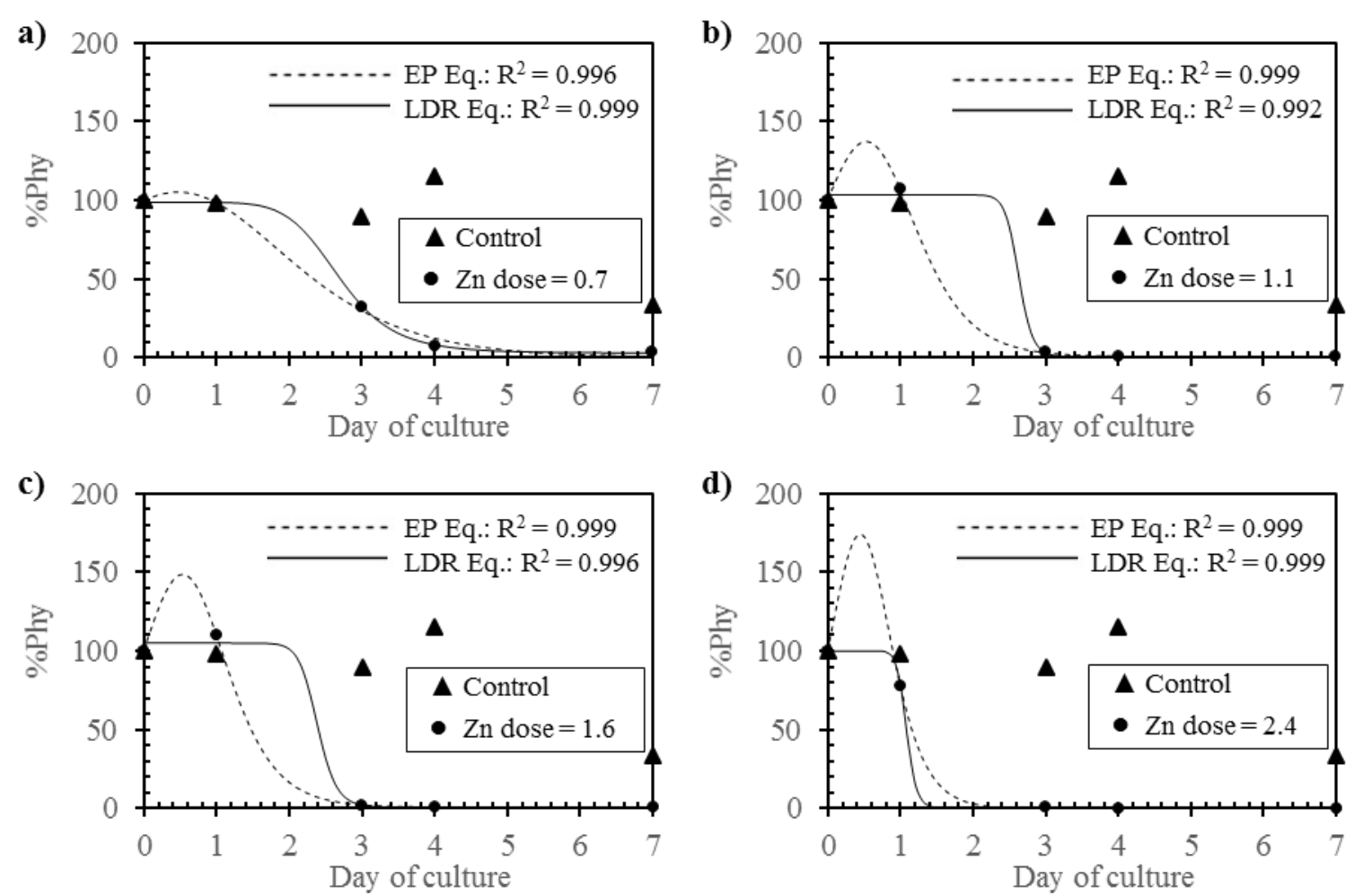

Figure 2. \% Phy levels in ASB waters without and with $\mathrm{Zn}$ subsequently added at various concentrations (a) 0.7 , (b) 1.1 , (c) $1.6 \&$ (d) \& $2.4 \mathrm{mg} / \mathrm{L} \mathrm{Zn}$
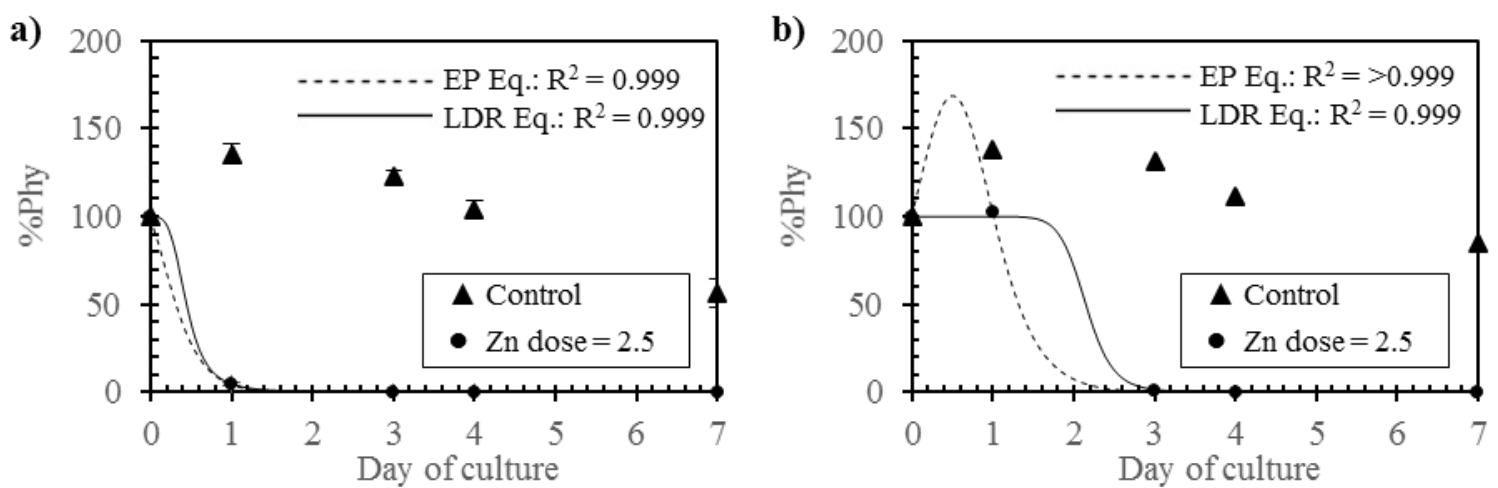

Figure 3. \%Phy levels in ASB waters without and with $\mathrm{Zn}$ subsequently added at $2.5 \mathrm{mg} / \mathrm{L}$ spiked with initial phycocyanin at a) $46 \mu \mathrm{g} / \mathrm{L}$ and b) $86 \mu \mathrm{g} / \mathrm{L}$

From Expt \#2 conducted to investigate the effect of the initial MA338 level (based on phycocyanin levels, $86 \mathrm{vs} 46 \mu \mathrm{g} / \mathrm{L}$ ) on the capacity of $\mathrm{Zn}$ (at a selected dose, of $2.5 \mathrm{mg} / \mathrm{L}$ ) to inhibit this cyanobacteria (Figure 3), the decay rates were found to have an inverse correlation with the $\mathrm{Zn}$ :initial phycocyanin ratio, as expected. Samples inoculated with MA338 at $46 \mu \mathrm{g} / \mathrm{L}$ initial phycocyanin concentration showed higher decay rates (by EP: $+14 \%$; by LDR: $+29 \%$ ) than their corresponding samples with $86 \mu \mathrm{g} / \mathrm{L}$ initial phycocyanin.

Further, the $t_{50}$ values for samples at $46 \mu \mathrm{g} / \mathrm{L}$ initial phycocyanin were found to be lower (by EP: $-77 \%$; by LDR: $-81 \%$ ) than their corresponding values for samples at $86 \mu \mathrm{g} / \mathrm{L}$ initial phycocyanin. The t90 values followed the same trend, being lower for samples with $46 \mu \mathrm{g} / \mathrm{L}$ initial phycocyanin (by EP: $-58 \%$; by LDR: $-68 \%$ ) compared to their corresponding values for samples with $86 \mu \mathrm{g} / \mathrm{L}$ initial phycocyanin. This demonstrates that the impact of $\mathrm{Zn}$ is a function of the amount of $\mathrm{Zn}$ exposed to MA338 biomass.

From Expt \#3 conducted to compare the effect of $\mathrm{Zn}($ at $2.5 \mathrm{mg} / \mathrm{L})$ on the two different cyanobacterial species (Pseudanabaena spp. and MA338), it was found that $\mathrm{Zn}$ similarly impacted both species based on loss of phycocyanin by Day 3 (Figure 4). Although the EP model was fitted to the Pseudanabaena spp. data, then assuming a maximum phycocyanin response level greater than at Day 0 , the acquired data at Day 1 indicates no increase and further that the LDR function is a better representation of that data (Figure 4a). This is in 
contrast to data of MA338, where phycocyanin levels consistently increased from Day 0 to Day 1, and the EP model is the better of the two models. The dynamics of phycocyanin levels in the controls varied, and with both declining to low percentages of original levels by Day 7. Samples inoculated with Pseudanabaena spp. and dosed with $\mathrm{Zn}$ had lower $\mathrm{t}_{50}$ values (EP: $-45 \%$; LDR: $-118 \%$ ) than corresponding samples inoculated with the MA338. The t90 values for samples inoculated with Pseudanabaena spp. are lower (EP: -41\% and LDR: $87 \%$ ) compared with corresponding values for samples inoculated with MA338. Further investigation is needed to determine if phycocyanin dynamics of cyanobacteria upon exposure to $\mathrm{Zn}$ is specie specific and if so, which model function provides the best description for a particular cyanobacterium.
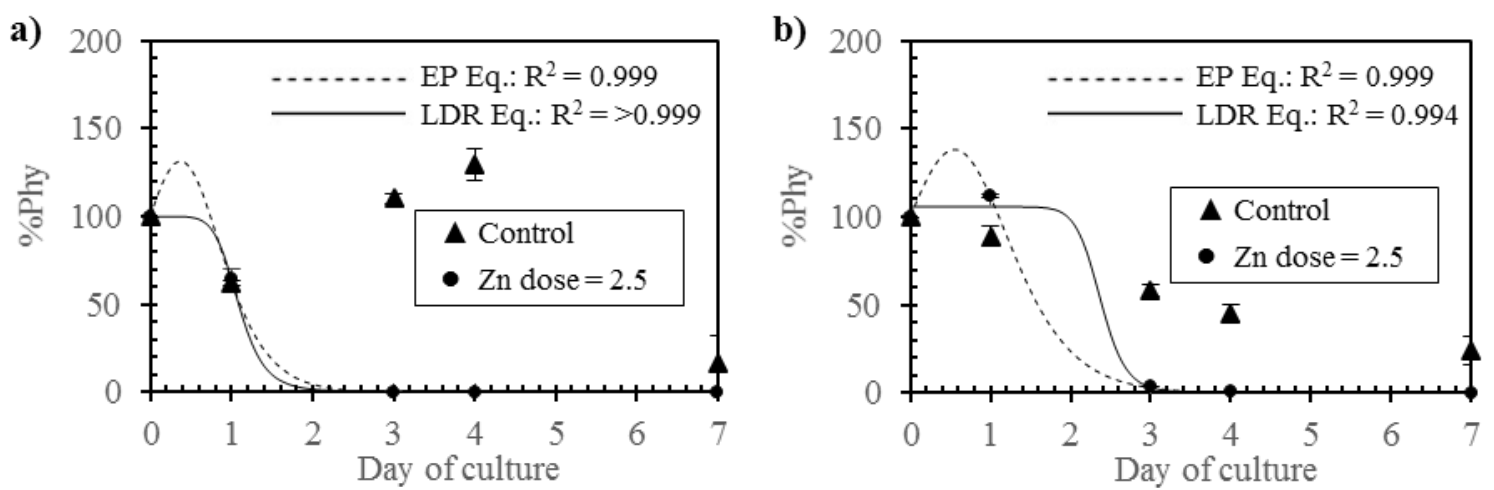

Figure 4. \%Phy levels in ASB waters with $\mathrm{Zn}$ subsequently added at $2.5 \mathrm{mg} / \mathrm{L}$ spiked with a) Pseudanabaena spp. and b) MA338 species

The EP model correctly described increase in phycocyanin after initial $\mathrm{Zn}$ exposure to MA338, but the maximum level fitted based on data from days 1, 3, 4 and 7 is speculative of what would be the actual value, i.e. the actual maximum value and occurrence time would require high-resolution data from the start of the experiment to $\sim 24 \mathrm{hr}$ of $\mathrm{Zn}$ exposure. The actual maximum phycocyanin level and when this occurs may be incidental in terms of the effect of $\mathrm{Zn}$ on the timeframe for the loss of phycocyanin to a minimum level but may be significant in terms of a toxicity response to an exposure time of a specific $\mathrm{Zn}$ concentration. Here, for MA338, the initial response that is evident is phycocyanin increase, presumably from cell lysis and/or as a defence response to $\mathrm{Zn}$ presence at stressor levels (Poliak et al. 2011).

In a study which investigated the effects of $\mathrm{Cu}, \mathrm{Ni}$ and $\mathrm{Zn}$ on two strains of $M$. aeruginosa (CALU 972 and 973) sourced from the Karelian lakes, Russia, Polyak et al. (2013) reported that addition of low $\mathrm{Zn}$ concentrations $(25-100 \mu \mathrm{g} / \mathrm{L})$ to a culture medium induced growth in both strains. This is in contrast to $\mathrm{Cu}$ and $\mathrm{Ni}$, where no concentration at or above $25 \mu \mathrm{g} / \mathrm{L}$ induced biomass growth was found (Polyak et al. 2013). Cyanobacteria culture medium ASM-1, (Gorham et al. 1964) has about $0.04 \mu \mathrm{g} / \mathrm{L} \mathrm{Cu}$ as a trace element. Polyak et al. (2013) reported $\mathrm{Cu}$ having the highest suppression to biomass growth of both strains tested, followed by $\mathrm{Ni}$ and then $\mathrm{Zn}$ (i.e. $50 \mu \mathrm{g} / \mathrm{L} \mathrm{Cu}, 225 \mu \mathrm{g} / \mathrm{L} \mathrm{Ni}$ and $250 \mu \mathrm{g} / \mathrm{L} \mathrm{Zn}$ ).

In our study, phycocyanin detection was used as an indicator of biomass growth, as well as of cell stress and lysis, and subsequent phycocyanin reduction. High percentage loss of phycocyanin was also empirically correlated with observed settling of cyanobacteria into a sludge layer, in batch test jars. Zeng et al. (2009) studied the acclimation of a strain of Microcystis aeruginosa (FACHB-905, [MA905] sourced from Lake Dianchi, China) to $\mathrm{Zn}$ (at up to $3.0 \times 10^{-8} \mathrm{M}\left[\mathrm{Zn}^{2+}\right]$ ) over 1 to 15 days. They found that intra-Zn concentrations in cells that were acclimated for different durations, were significantly greater than the controls, but reduced to about control levels after 5 days of recovery. Zeng et al. (2009) found that the MA905 became more tolerant of metal toxicity following acclimation using the highest $\mathrm{Zn}$ concentration tested $\left(3.0 \times 10^{-8} \mathrm{M}\left[\mathrm{Zn}^{2+}\right]\right.$. However, they found that the cyanobacterium became very sensitive following 1 day of recovery, while the tolerance of the acclimated-recovered cyanobacterial cells was comparable to the controls following 5 days of recovery. Their findings demonstrated potential responses by M. aeruginosa to $\mathrm{Zn}$ exposure where this is at non-toxic levels, including acclimation and efflux. In our study $\mathrm{Zn}$ concentrations tested were much higher than those assessed by Zeng et al. (2009), and in the toxic range. The effect of $\mathrm{Zn}$ on cyanobacteria is highly dependent on concentration ranging from it being an essential metal, a stressor and to being toxic. Application of $\mathrm{Zn}$ for suppression of cyanobacteria would need to ensure concentrations are applied and maintained at levels that are toxic, and avoidance of levels that support growth. 


\section{CONCLUSIONS}

We propose that this modelling approach integrated with in-situ phycocyanin detection enables improved understanding of $\mathrm{Zn}$ as a potential cyanobacterial control agent as well as understanding its importance where it occurs as an apparent background metal in industrial wastewaters. Although both model equations used in this study broadly simulated the dynamics of phycocyanin in samples of PML wastewaters in response to $\mathrm{Zn}$ exposure between 0.7 and $2.4 \mathrm{mg} / \mathrm{L}$, further investigation is needed at particular times of exposure. Initial assessment involved data collections on days 1, 3, 4 and 7 with maximum effect (based on complete loss of phycocyanin) evident by day 4 . However, the results obtained so far show that higher resolution data is needed to understand better the response of cyanobacteria to $\mathrm{Zn}$ from initial exposures (within 1 day). Further, determination is needed of the effective period of cyanobacteria exposure time to $\mathrm{Zn}$ at specific concentration to cause a toxicity response (phycocyanin loss) i.e. integration of $\mathrm{Zn}$ concentration over exposure time. The magnitude of the peak in phycocyanin levels is speculative based on low resolution data available and where the phycocyanin levels exceed the initial levels. To address this, phycocyanin levels would need to be monitored at higher resolution but this presents logistical challenges in batch experiments. Any consideration of the use of $\mathrm{Zn}$ as a cyanobacteria control agent needs to account for the potential of low concentrations of $\mathrm{Zn}$ inducing growth. Low level ambient $\mathrm{Zn}$ in the PML wastewaters, with low colour and adequate nutrients might explain in part, the basis for the occurrences of cyanobacterial blooms in the PML wastewaters.

\section{ACKNOWLEDGMENTS}

We thank Mr Malcolm Abbott for sample collection and analyses, Mr Graham Burch and Mr Josef Marzouk for project direction and Ms Sandy Dickson and Mr Cédric Dajnak for support in laboratory investigations.

\section{REFERENCES}

ANZECC (2000). Australian and New Zealand guidelines for fresh and marine water quality. Australian and New Zealand Environment and Conservation Council and Agriculture and Resource Management Council of Australia and New Zealand, Canberra: 1-103.

Butler, N., J.C. Carlisle, R. Linville, B. Washburn (2009). Microcystins: a brief overview of their toxicity and effects, with special reference to fish, wildlife, and livestock. California Environmental Protection Agency, Sacramento; 5 .

Gorham, P, J. McLachlan, U. Hammer, W. Kim (1964). Isolation and culture of toxic strains of Anabaena flosaquae (Lyngb.) De Breb. Verh. Internal. Verein. Limnol 19, 796-804.

Iwinski, K.J., A.J. Calomeni, T.D. Geer, J. H. Rodgers (2016). Cellular and aqueous microcystin-LR following laboratory exposures of Microcystis aeruginosa to copper algaecides. Chemosphere, 147: 74-81.

Kirkwood, A. E., C. Nalewajko, R. R. Fulthorpe (2003). Physiological characteristics of cyanobacteria in pulp and paper waste-treatment systems. Journal of Applied Phycology 15(4), 325-35.

Lewis, R., J. Cohen, J. Awad, H. Burger, J. Marzouk, G. Burch, D. Lewis, J. van Leeuwen (2018). Study of the impacts of process changes of a pulp and paper mill on aerated stabilization basin (ASB) performance. Chemosphere 211, 767-774

Mahmood, T., M. Paice (2006). Aerated stabilization basin design and operating practices in the Canadian pulp and paper industry. Journal of Environmental Engineering and Science 5(5), 383-95.

Poliak, Y., T. Zaytseva, V. Petrova, N. Medvedeva (2011). Development of mass cyanobacteria species under heavy metals pollution. Hydrobiological Journal 47(3).

Polyak, Y, T. Zaytseva, N. Medvedeva (2013). Response of toxic cyanobacterium Microcystis aeruginosa to environmental pollution. Water, Air, \& Soil Pollution 224, 1494.

World Health Organization (2015). Management of cyanobacteria in drinking-water supplies: information for regulators and water suppliers.

Zeng, J., W-X. Wang (2011). Temperature and irradiance influences on cadmium and zinc uptake and toxicity in a freshwater cyanobacterium, Microcystis aeruginosa. Journal of hazardous materials 190, 922-929.

Zeng, J., L. Yang, W-X. Wang (2009). Acclimation to and recovery from cadmium and zinc exposure by a freshwater cyanobacterium, Microcystis aeruginosa. Aquatic toxicology 93, 1-10.Zeng, J, Yang, L \& Wang, W-X 2009, 'Acclimation to and recovery from cadmium and zinc exposure by a freshwater cyanobacterium, Microcystis aeruginosa', Aquatic toxicology, vol. 93, no. 1, pp. 1-10. 